\title{
IFN $\gamma$ contributes to the development of gastric epithelial cell metaplasia in Huntingtin interacting protein 1 related (Hip1r)-deficient mice
}

\author{
Zhiping Liu', Elise S Demitrack', Theresa M Keeley ${ }^{1}$, Kathryn A Eaton², Mohamad El-Zaatari ${ }^{3}$, \\ Juanita L Merchant ${ }^{1,3}$ and Linda C Samuelson ${ }^{1,3}$
}

Huntingtin interacting protein 1 related (Hip1r) is an F-actin- and clathrin-binding protein involved in vesicular trafficking that is crucial for parietal cell function and epithelial cell homeostasis in the stomach. Gastric parietal cells in Hip1rdeficient mice are lost by apoptotic cell death, which leads to a progressive epithelial cell derangement, including glandular hypertrophy, zymogenic cell loss and expansion of a metaplastic mucous cell lineage known as spasmolytic polypeptide-expressing metaplasia (SPEM). The epithelial cell changes are associated with infiltration of inflammatory cells. As inflammatory mediators, such as IFN $\gamma$, have been shown to contribute to the development of the gastric epithelial cell metaplasia after Helicobacter infection, we tested whether IFN $\gamma$ played a role in the spontaneous progressive epithelial metaplasia observed in Hip1r-deficient mice. Hip1r-deficient mice were crossed with IFN $\gamma$-deficient mice and single- and double-mutant mice were analyzed at 3 and 12 months of age. Histopathology scoring showed that loss of IFN $\gamma$ tempered the spontaneous development of metaplastic lesions in Hip1r-deficient mice. Loss of IFN $\gamma$ was observed to abrogate the glandular hypertrophy evident in Hip1r mutant stomach, although increased epithelial cell proliferation and elevated gastrin levels were not affected by the presence or absence of this pro-inflammatory cytokine. An analysis of cell lineage markers in the double-mutant mice demonstrated that IFN $\gamma$ specifically affected the development of metaplastic mucous cells in the neck region, whereas the parietal cell, surface mucous cell and zymogenic cell alterations remained similar to the histopathology in the Hip1r mutant. Morphometric analysis showed that IFN $\gamma$ was required for the mucous cell hypertrophy and hyperplasia observed in Hip1r-deficient mice. Together, these findings demonstrate that IFN $\gamma$ is critical for the development of the gastric epithelial cell metaplasia that results from parietal cell atrophy in the Hip1r-deficient mice.

Laboratory Investigation (2012) 92, 1045-1057; doi:10.1038/labinvest.2012.73; published online 23 April 2012

KEYWORDS: atrophic gastritis; gastric cancer; mucous neck cell; parietal cell; spasmolytic polypeptide-expressing metaplasia (SPEM); stomach

Gastric cancer is the second most common cause of cancerrelated death worldwide. ${ }^{1}$ Human gastric epithelial cell transformation and eventual gastric cancer development are thought to result from a chronic inflammatory condition initiated by Helicobacter pylori infection. ${ }^{2}$ The current pathway for gastric cancer development, as proposed by Correa ${ }^{3}$ and others, ${ }^{4}$ is a progression from inflammation-induced changes in the gastric mucosa to chronic and then atrophic gastritis associated with the loss of parietal cells, with subsequent metaplastic changes including the formation of spasmolytic polypeptide-expressing metaplasia (SPEM) and/ or intestinal metaplasia. Parietal cells in particular are considered to play a critical role in gastric epithelial cell homeostasis, as evidenced by disturbed epithelial cell differentiation in mouse models of parietal cell loss, including reduced numbers of zymogenic cells and expansion of an aberrant mucous cell population termed SPEM that emerges from cells of the zymogenic lineage. ${ }^{5,6}$ These characteristic epithelial cell changes have been observed in numerous mouse models of parietal cell loss, including those exhibiting

\footnotetext{
${ }^{1}$ Department of Molecular and Integrative Physiology, University of Michigan, Ann Arbor, MI, USA; ${ }^{2}$ Laboratory Animal Medicine Unit, University of Michigan, Ann Arbor, MI, USA and ${ }^{3}$ Department of Internal Medicine, University of Michigan, Ann Arbor, MI, USA

Correspondence: Dr LC Samuelson, PhD, Department of Molecular and Integrative Physiology, University of Michigan, 2041 BSRB, 109 Zina Pitcher Place, Ann Arbor, MI 48109-2200, USA.

E-mail: Icsam@umich.edu

Received 10 October 2011; revised 13 March 2012; accepted 13 March 2012
} 
parietal cell death induced by toxins ${ }^{6,7}$ or gene mutation, ${ }^{8}$ as well as those with progressive cell loss resulting from activation of complex inflammatory pathways, including autoimmune gastritis ${ }^{9,10}$ or infection with gastric pathogenic Helicobacter sp. ${ }^{11}$ The common cellular derangement observed in all of these divergent pathological processes strongly suggests that parietal cell function is necessary for gastric epithelial cell homeostasis.

We have recently described a mouse mutant with spontaneous parietal cell apoptosis that serves as a useful model to study the complex gastric epithelial cell changes initiated by parietal cell loss. Huntingtin interacting protein 1 related (Hiplr) is an F-actin- and clathrin-binding protein involved in the dynamic vesicular trafficking associated with parietal cell acid secretion. ${ }^{8}$ Loss of Hip1r results in parietal cell apoptosis, with subsequent spontaneous development of multifaceted gastric epithelial cell changes, including glandular hypertrophy, expansion of surface mucous cells and disruption of the zymogenic lineage characterized by loss of zymogenic chief cells, expansion of cells that co-stain for chief and mucous neck cell markers and emergence of metaplastic mucous cells. ${ }^{8,12}$ The loss of zymogenic cells accompanied by the expansion of metaplastic TFF2-expressing mucous cells is diagnostic for SPEM. Importantly, Hip1r-deficient mice have an associated gastric inflammatory cell infiltration, possibly resulting from low gastric acid levels creating conditions permissive for bacterial overgrowth. ${ }^{8}$ However, it is still unknown if and how inflammation might play a role in the multilineage epithelial cell derangement associated with parietal cell loss.

It is well established that chronic inflammation is crucial for the initiation and progression of epithelial cell metaplasia and gastric cancer development. However, the roles of specific inflammatory mediators in this complex process are not clear. Clinical studies have shown that specific gene polymorphisms for interleukin-1 $\beta$ (IL-1 $\beta$ ) are associated with increased cytokine levels and increased incidence of gastric cancer. ${ }^{13,14} \mathrm{In}$ deed, expression of IL-1 $\beta$ in the gastric mucosa of transgenic mice triggered spontaneous gastric inflammation and gastric cancer development, which was accelerated after Helicobacter felis infection. ${ }^{15}$ Together, these studies suggest that IL-1 $\beta$ can induce gastric neoplasia, but the roles for other pro-inflammatory cytokines remain to be described.

An analysis of cytokine profiles in mice after $H$. pylori infection suggested that mucosal inflammation is Th1 mediated, characterized by increased expression of the proinflammatory cytokine interferon- $\gamma$ (IFN $\gamma){ }^{16,17}$ Further support for the potential importance of this cytokine was provided by the observation of increased expression of direct IFN $\gamma$ target genes in mouse gastric epithelial cell populations after $H$. pylori infection ${ }^{18}$ and by the observation of reduced metaplasia in Helicobacter-infected IFN $\gamma$-deficient mouse models. ${ }^{16,17,19,20}$ Furthermore, treatment of C57BL/6 mice with IFN $\gamma$ induced the expansion of mucous cells with features similar to SPEM. ${ }^{21}$ In addition, characterization of responses to IFN $\gamma$ in the human gastric cancer cell line
NCI-N87 showed increased expression of the mucous neck cell markers TFF2 and Muc6, which are also upregulated in SPEM. ${ }^{21}$ Together, these data suggested that IFN $\gamma$ might play a role in the development of SPEM in response to gastric inflammation.

Although IFN $\gamma$ has been strongly implicated in the epithelial cell remodeling in response to Helicobacter infection, its role in mediating the gastric epithelial cell lineage changes in response to parietal cell loss has not been investigated. Thus, in this study we examined the role of IFN $\gamma$ for the spontaneous development of metaplasia in Hip1r-deficient mice by crossing this mutant with IFN $\gamma$-deficient mice to generate Hip1r/IFN $\gamma$ double-mutant mice. We found that IFN $\gamma$ deficiency markedly reduced the gastric histological lesions and reduced the mucous cell metaplasia normally observed in Hip1r mutant mice. Importantly, these studies establish IFN $\gamma$ as a critical cytokine contributing to the formation of SPEM in Hiplr-deficient mice.

\section{MATERIALS AND METHODS \\ Mice}

Mice were generated by crossing Hip1r-deficient mice ${ }^{22}$ with IFN $\gamma$-deficient mice (Jackson Lab, no. 002287). Mice were on a mixed 129X1 and C57BL/6 strain background, and all groups were composed of littermates generated from intercrossing compound heterozygotes. Control, Hip1r-deficient, Hip1r/IFN $\gamma$ double-mutant mice and IFN $\gamma$-deficient mice of both sexes were examined at 3 and 12 months of age. Hip1r and IFN $\gamma$ heterozygotes $(+/-)$ did not exhibit gastric phenotypes and thus were grouped with mice carrying wild-type alleles $(+I+)$. Thus, the control group included homozygous wild type and heterozygotes at both loci, which all exhibited similar phenotypes. IFN $\gamma$-deficient mice did not differ from controls for the phenotypes examined in this study. Mice were housed in ventilated and automated watering cages under specific pathogen-free conditions. Mouse use was approved by the University of Michigan Committee on Use and Care of Animals.

\section{Histological Analysis}

Stomachs were removed after an overnight fast and fixed in $4 \%$ paraformaldehyde as described previously. ${ }^{10}$ The analysis focused on the corpus region from the greater curvature. Paraffin tissue sections $(5 \mu \mathrm{m})$ were stained with hematoxylin and eosin (H\&E) to evaluate general histology and with periodic acid Schiff (PAS) and Alcian blue to evaluate mucin type changes. Histological scores were blindly evaluated by an experienced veterinary pathologist based on the following six parameters: mucosal hypertrophy, mucous cell metaplasia, dilated glands, disorganized glands, granulocytes and mononuclear cell infiltrates. Lesions were scored on a semiquantitative scale of 0 to 3. Lesion absence in all six categories was given a score of 0 . For mucosal hypertrophy, detectable thickening was scored 1 , up to $2 \times$ normal thickness was scored 2, and thickening $>2 \times$ was given a score of 3 . For 
mucous cell metaplasia, the presence of a few 'foamy' epithelial cells was scored 1 , foamy cells in most fields but with visible normal tissue was scored 2 , and sections where the glandular epithelium was replaced by foamy mucous cells was scored 3. For the presence of dilated glands, occasional dilated glands was scored $1,>4$ dilated glands per section was scored 2, and dilated glands that were present in all fields was scored 3. Tissue with detectable disorganized glands was scored 1, prominent but not widespread gland disorganization was scored 2, and disorganized glands that were present in all fields was scored 3. For granulocytes and mononuclear inflammatory cells, the presence of occasional clusters or widely scattered cells was scored 1, the presence of many clusters or focal extensive infiltrates was scored 2, and inflammatory cells present in all fields was scored 3.

Specific gastric cell types were identified by immunostaining for $\mathrm{H}^{+}, \mathrm{K}^{+}$-ATPase $\alpha$-subunit (1:1000; Medical and Biological Laboratories, Aichi, Japan), mucin-5AC (Muc5AC 1:75; Novocastra, Newcastle, UK), gastric intrinsic factor (1:2000 rabbit anti-human intrinsic factor; gift from David Alpers, Washington University, St Louis, MO, USA) and IFN $\gamma$ receptor 2 (IFNGR2 1:10; rabbit polyclonal; Santa Cruz, CA, USA), and visualized with appropriate secondary antibodies as previously described. ${ }^{10}$ Griffonia simplicifolia lectin II (GSII 1:1000; Invitrogen Alexa 488 conjugated) was used to stain for mucous cells and 4',6-diamidino-2-phenylindole dihydrochloride (DAPI) was used for counterstaining cell nuclei. Imaging by digital microscopy was performed as previously described. ${ }^{10}$

Proliferating cells were analyzed by immunostaining for Ki67 (1:200; Thermo Scientific, Waltham, MA, USA). Image J (1.34u by Wayne Rasband, NIH, USA; http://rsb.info.nih.gov/ $\mathrm{ij} /$ ) was used to calculate the number of Ki67-positive cells per gland. To identify proliferating mucous cells, tissue sections were immunostained for Ki67 as above, rinsed with $0.01 \%$ Triton X-100 in PBS and then stained with GSII (1:1000 Alexa 594) $1 \mathrm{~h}$ at room temperature. Secondary antibody staining was performed with goat anti-rabbit IgG Alexa 488 (1:400; Invitrogen) and slides were mounted with Prolong Gold Antifade Reagent with DAPI. Images were collected on a confocal microscope (Zeiss LSM510, Carl Zeiss, Jena, Germany).

\section{Confocal Analysis of Mucous Cells}

Tissue sections were co-immunostained for E-cadherin $(72 \mathrm{~h}$, $4{ }^{\circ} \mathrm{C}$ at 1:1000; rat monoclonal from Invitrogen), rinsed with $0.01 \%$ Triton X-100 in PBS and then stained with GSII. Secondary antibody staining was performed with goat antirat IgG Alexa 488 (1:400; Invitrogen) and slides were mounted with Prolong Gold with DAPI. Confocal images were analyzed for mucous cell size and number using Image J software. For quantification of cell size, only cells with a distinctly visible cell membrane (E-cadherin positive), positive GSII staining and a nucleus in the plane of section were counted (2-3 animals per group). For quantification of cell number, GSII-positive cells per gastric gland were counted from two to three representative fields per animal. Similar to the analysis above, only those cells with a visible cell membrane, positive GSII staining and a nucleus in the plane of section were included.

\section{Measurement of Serum Gastrin}

Radioimmunoassay (RIA) was used to measure serum gastrin levels as previously described. ${ }^{8}$ Briefly, blood was collected from fasted mice by cardiac puncture into heparinized tubes, and plasma was stored at $-20^{\circ} \mathrm{C}$ until assayed. Samples were incubated with $\left[{ }^{125} \mathrm{I}\right]-\mathrm{Tyr} 12-$ Gastrin I (human; Perkin Elmer Life and Analytical Sciences) and rabbit anti-gastrin antibody $(1.27 \mu \mathrm{g} / \mathrm{ml}$ final concentration; DakoCytomation) for $72 \mathrm{~h}$ at $4{ }^{\circ} \mathrm{C}$, and gastrin was harvested by polyethylene glycol precipitation and centrifugation. Gastrin levels were calculated from the pellet radioactivity in comparison with a standard curve $(2-500 \mathrm{pmol} / \mathrm{l}$; human synthetic gastrin I diluted in heat-treated mouse serum; both from Sigma-Aldrich). The gastrin antibody recognizes both nonsulfated and sulfated forms of gastrin-17 and gastrin-34.

\section{qRT-PCR Measurement of mRNA Abundance}

Quantitative reverse transcriptase-PCR (qRT-PCR) amplification of gastric epithelial-specific markers was performed as previously described. ${ }^{12}$ Briefly, total RNA was isolated from corpus or antrum and reverse transcribed into cDNA using the iScript cDNA Synthesis Kit (Bio-Rad, Hercules, CA, USA). Triplicates for each sample were amplified by PCR to measure mRNA abundance of specific genes. Expression levels were normalized to the expression of the gene for glyceraldehyde 3-phosphate dehydrogenase (Gapdh), which remained the same in all groups. All primers used for qRTPCR assays were validated via standard curve of a dilution series as previously described. ${ }^{8}$

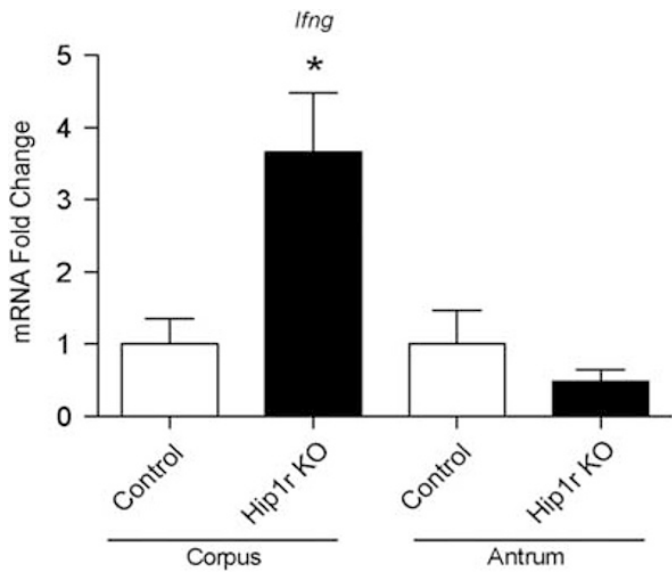

Figure 1 Increased IFN $\gamma$ gene expression in Hip1r-deficient (KO) mice. Quantitative reverse transcriptase-PCR (qRT-PCR) measurement of IFN (Ifng) gene expression from corpus and antrum of 3-month-old control $(n=4)$ and Hip1r-KO $(n=5)$ mice. Values were normalized to glyceraldehyde 3-phosphate dehydrogenase (Gapdh) levels and expressed as fold change (mean \pm s.e.m) relative to control values for each region and analyzed using Student's $t$-test $\left({ }^{*} P<0.05\right.$ vs corpus control). 

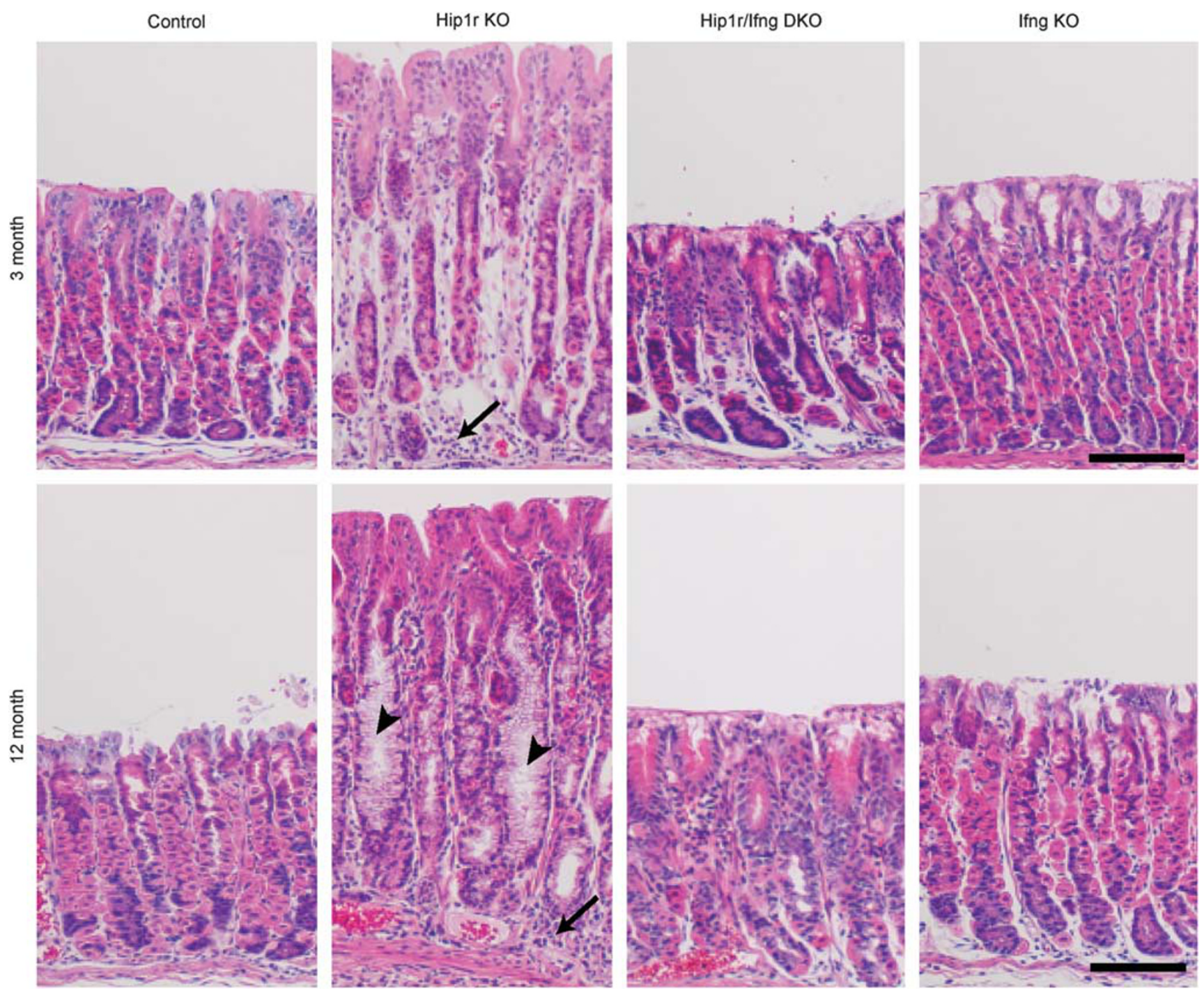

Figure 2 Spontaneous development of gastric metaplasia in Hip1r-deficient mice requires IFN $\gamma$. Paraffin sections from the corpus of control, Hip1r-KO, Hip1r/IFN $\gamma$-DKO and IFN $\gamma$-KO mice at 3 and 12 months of age were stained with hematoxylin and eosin to evaluate general histology. Several aspects of the cellular changes that spontaneously developed in the Hip1r-KO, including inflammatory cell infiltrates (arrows) and mucous cell metaplasia (arrowheads), were not observed in the Hip1r/IFN $\gamma$-DKO stomachs. Note that IFN $\gamma$-KO mice were indistinguishable from control. Scale bars: $100 \mu \mathrm{m}$.

\section{Statistics}

GraphPad Prism software (v5.0, San Diego, CA, USA) was used for statistical analysis and preparation of graphs. Histological scores were analyzed by nonparametric MannWhitney $U$-test, and other data were analyzed by Student's $t$-test or one-way ANOVA, with Bonferroni's post-hoc test. Quantitative data were presented as mean \pm s.e.m. $P<0.05$ was considered significant.

\section{RESULTS}

IFN $\gamma$ Deficiency Reduced Gastric Histological Lesions of Hip1r-Deficient Mice

We determined whether increased IFN $\gamma$ was a component of the inflammatory response that spontaneously develops in the stomachs of Hip1r-deficient mice by quantitative measurement of mRNA abundance. This analysis revealed increased expression of IFN $\gamma$ in the acid-secreting corpus, but not the antrum of 3-month-old Hip1r-deficient mice in comparison with control mice (Figure 1).

To study the specific function of IFN $\gamma$ in the development of gastric metaplasia, Hip1r-deficient mice were crossed with IFN $\gamma$-deficient mice to generate Hip1r/IFN $\gamma$ doublemutant mice. Four genotypes were aged to 3 and 12 months, including control, Hip1r-deficient, Hip1r/IFN $\gamma$ double-mutant and IFN $\gamma$-deficient, and histology was examined by H\&E staining. As previously described, ${ }^{8,12}$ Hip1r-deficient mice spontaneously developed hypertrophy and inflammatory cell infiltration at 3 months of age (Figure 2). In contrast, Hip1r/IFN $\gamma$ double-mutant mice had reduced hypertrophy and inflammation, although the cellular morphology was still 


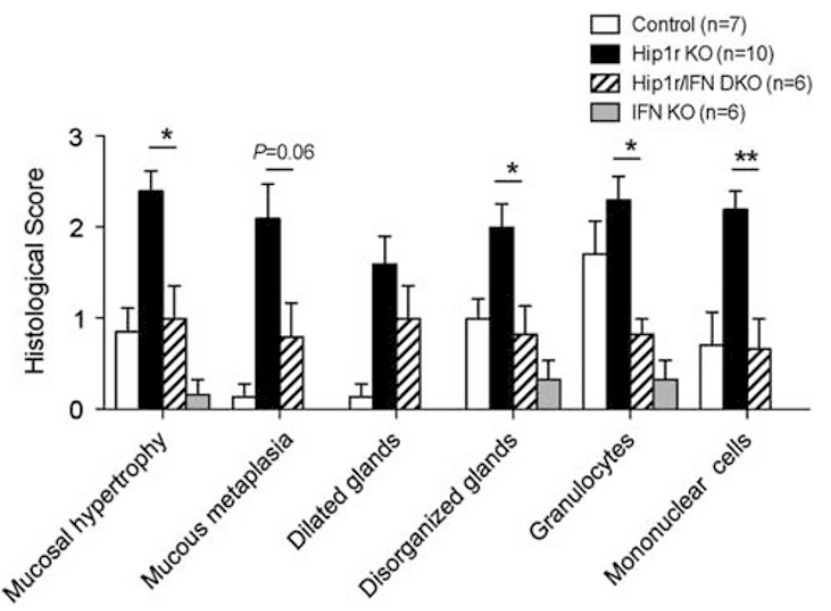

Figure 3 Histopathology in Hip1r-KO mouse stomach was reduced by IFN $\gamma$ deficiency. Histological scoring of $\mathrm{H} \& \mathrm{E}-$ stained gastric paraffin sections from 12-month-old control, Hip1r-KO, Hip1r/IFN $\gamma$-DKO and IFN $\gamma$-KO mice are displayed. Severity scores were determined for six different histological lesion categories and displayed as mean \pm s.e.m., with $n=6-10$ as shown. Statistical comparisons were analyzed using Mann-Whitney U-test; ${ }^{*} P<0.05,{ }^{* * P}<0.01 \mathrm{Hip} 1 \mathrm{r}$-KO vs Hip1r/IFN $\gamma$-DKO in the same category. altered in comparison with controls (described below). At 12 months of age, Hip1r-deficient mice exhibited more extensive hypertrophy and inflammation (arrows) as well as prominent mucous cell metaplasia (arrowheads), whereas Hip1r/IFN $\gamma$ double mutants were spared these phenotypes (Figure 2). Histological scoring confirmed that Hip1r/IFN $\gamma$ double-mutant mice exhibited a reduction of histological lesions across multiple parameters, with statistically significant differences in mucosal hypertrophy, disorganized glands, granulocytes and mononuclear cells (Figure 3). Together, these results showed that IFN $\gamma$ significantly contributes to the development of gastric gland pathology and inflammation in Hip1r-deficient mice.

\section{Epithelial Cell-Specific Effects of IFN $\gamma$}

To define the cellular targets of IFN $\gamma$-mediated metaplasia, gastric epithelial cell-specific markers were examined. Examination of parietal cells by immunostaining for the $\alpha$-subunit of the $\mathrm{H}^{+}, \mathrm{K}^{+}$-ATPase proton pump showed that Hip1r/IFN $\gamma$ double-mutant mice had a reduction in parietal cells, similar to that observed in Hiplr-deficient mice
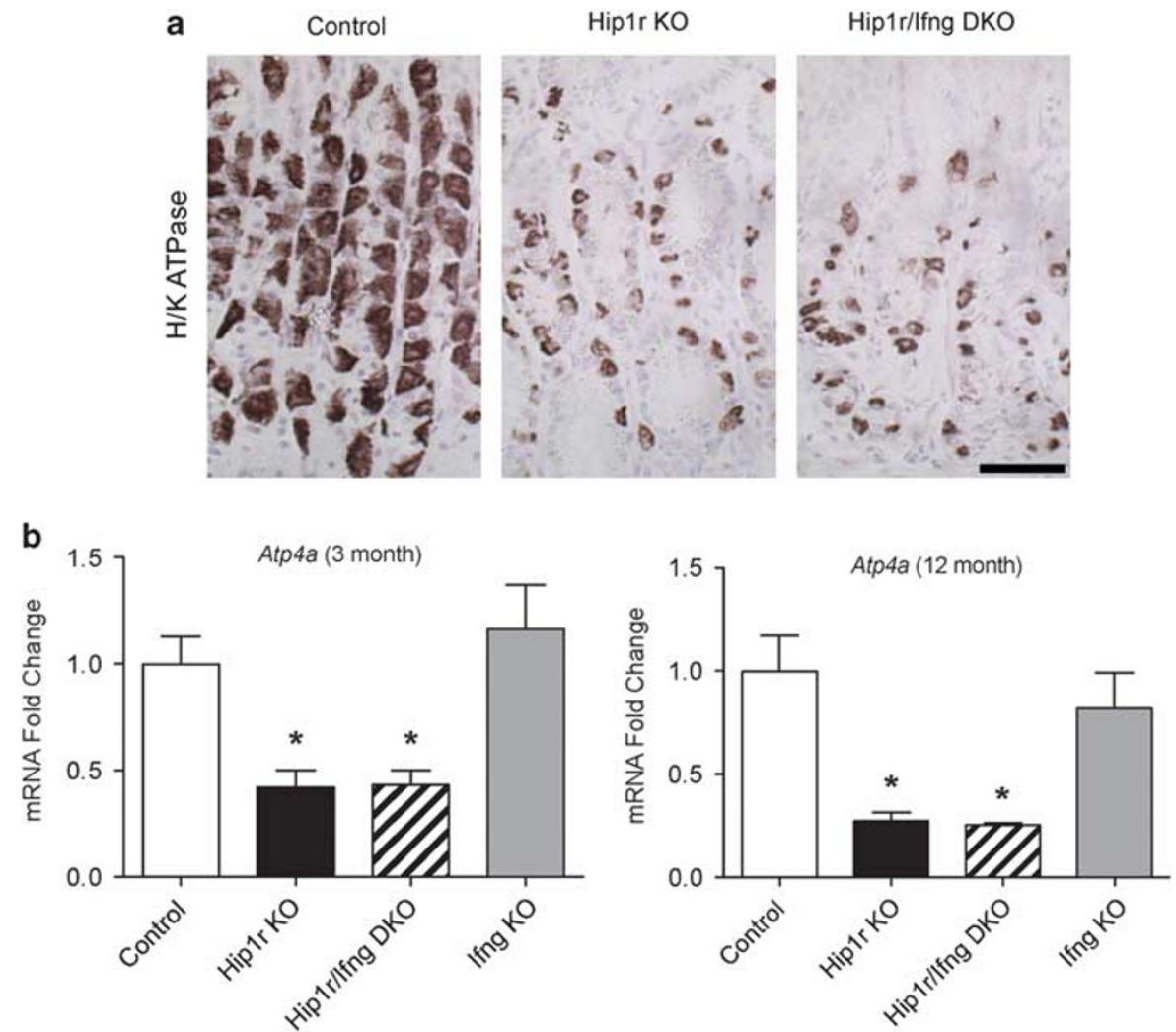

Figure 4 Parietal cell loss in Hip1r-deficient mice is not IFN $\gamma$ dependent. (a) Paraffin sections from the corpus of control, Hip1r-KO and Hip1r/IFN $\gamma$-DKO mice at 12 months of age were immunostained for the parietal cell specific marker $\mathrm{H}^{+}, \mathrm{K}^{+}$-ATPase $\alpha$-subunit. Scale bar: $100 \mu \mathrm{m}$. (b) Corpus mRNA abundance for the $\mathrm{H}^{+}, \mathrm{K}^{+}$-ATPase $\alpha$-subunit gene (Atp4a) in 3-month-old $(n=4-7)$ and 12-month-old $(n=3-5)$ mice was measured by qRT-PCR. Values were normalized to Gapdh and expressed as fold change (mean \pm s.e.m.) relative to control, with statistical analysis by one-way ANOVA with Bonferroni's post-hoc test $\left({ }^{*}<0.05\right.$ vs control). 


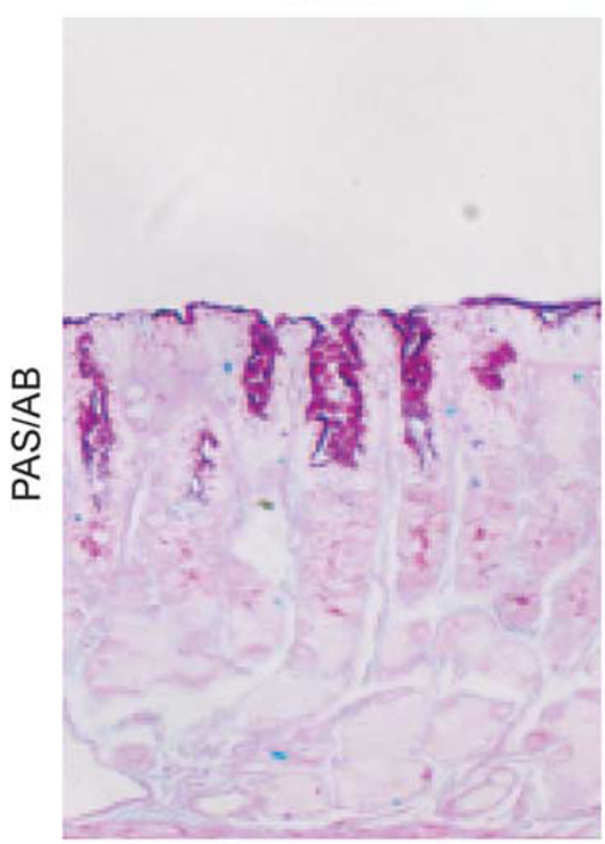

b

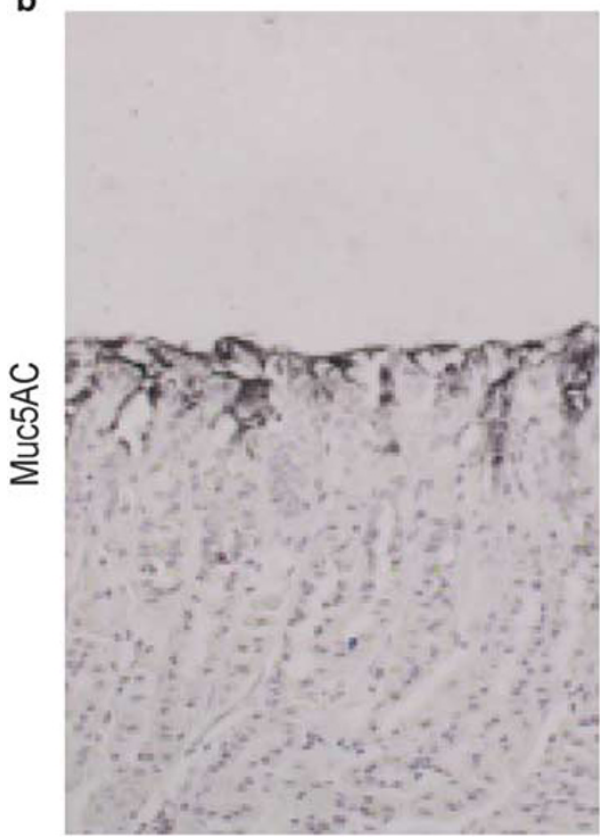

Hip1r KO
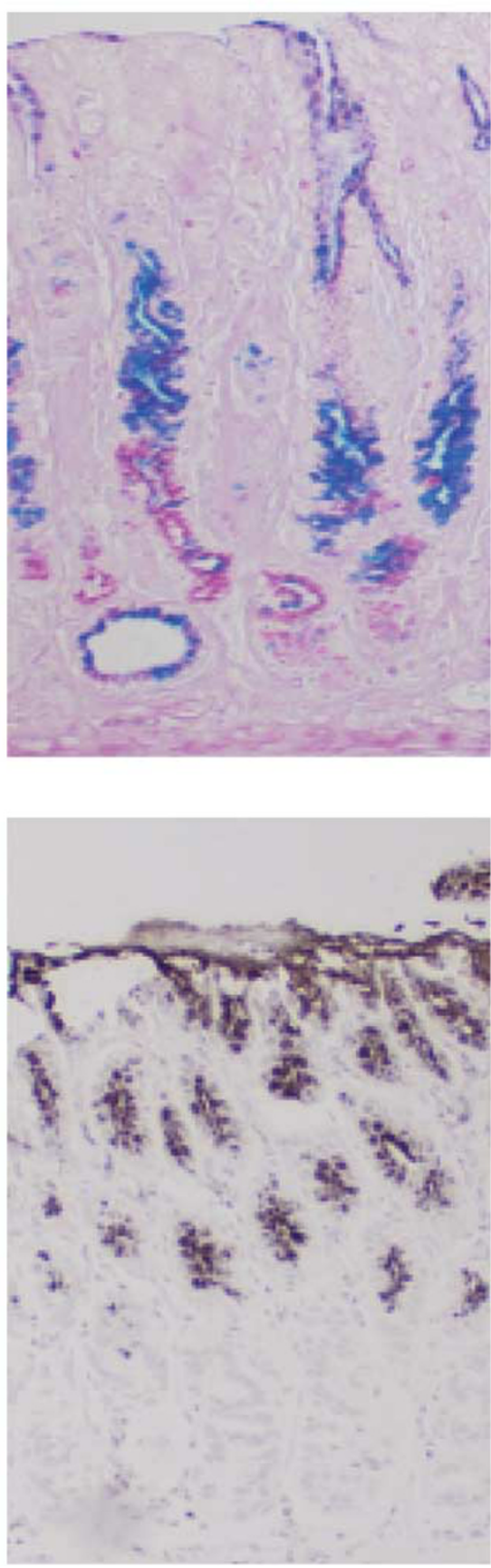

Hip1r/lfng DKO
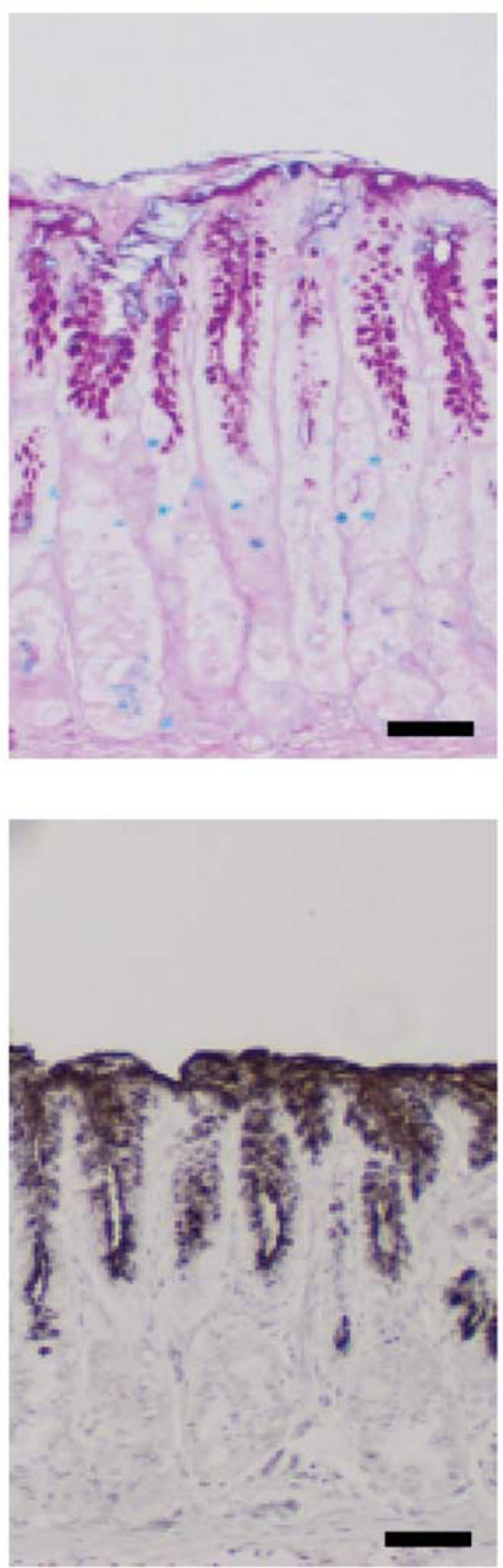

Figure 5 Expansion of surface mucous cells in Hip1r-deficient mice is not IFN $\gamma$ dependent. (a) To identify gastric mucins, paraffin sections from the corpus of control, Hip1r-KO and Hip1r/IFN $\gamma$-DKO mice at 12 months of age were stained with periodic acid Schiff/Alcian blue (PAS/AB). (b) Immunohistochemical staining for the surface mucous cell marker Muc5AC demonstrated that Hip1r/IFN $\gamma$-DKO mice exhibited similar increases in numbers of surface cells as observed in Hip1r-KO mice. Scale bars: $50 \mu \mathrm{m}$.

Figure 6 IFN $\gamma$ deficiency tempers the mucous cell metaplasia but does not affect the zymogenic cell loss observed in Hip1r-KO mice. (a) Paraffin sections from the corpus of control, Hip1r-KO and Hip1r/IFN $\gamma$-DKO mice at 3 and 12 months of age were co-stained with an antibody to the zymogenic cell marker gastric intrinsic factor (red) and the mucous cell-specific Griffonia simplicifolia lectin II (GSIl; green), with DAPI (blue) nuclear stain. Scale bar: $100 \mu \mathrm{m}$. (b) Corpus mRNA abundance for gastric intrinsic factor gene (Gif) expression in 3-month-old $(n=4-7)$ and 12-month-old ( $n=3-5)$ mice was measured by qRT-PCR. Values were normalized to Gapdh and expressed as fold change (mean \pm s.e.m.) relative to control with statistical analysis by one-way ANOVA with Bonferroni's post-hoc test $\left({ }^{*} P<0.05\right.$ and ${ }^{*} P<0.01$ vs control). 
a
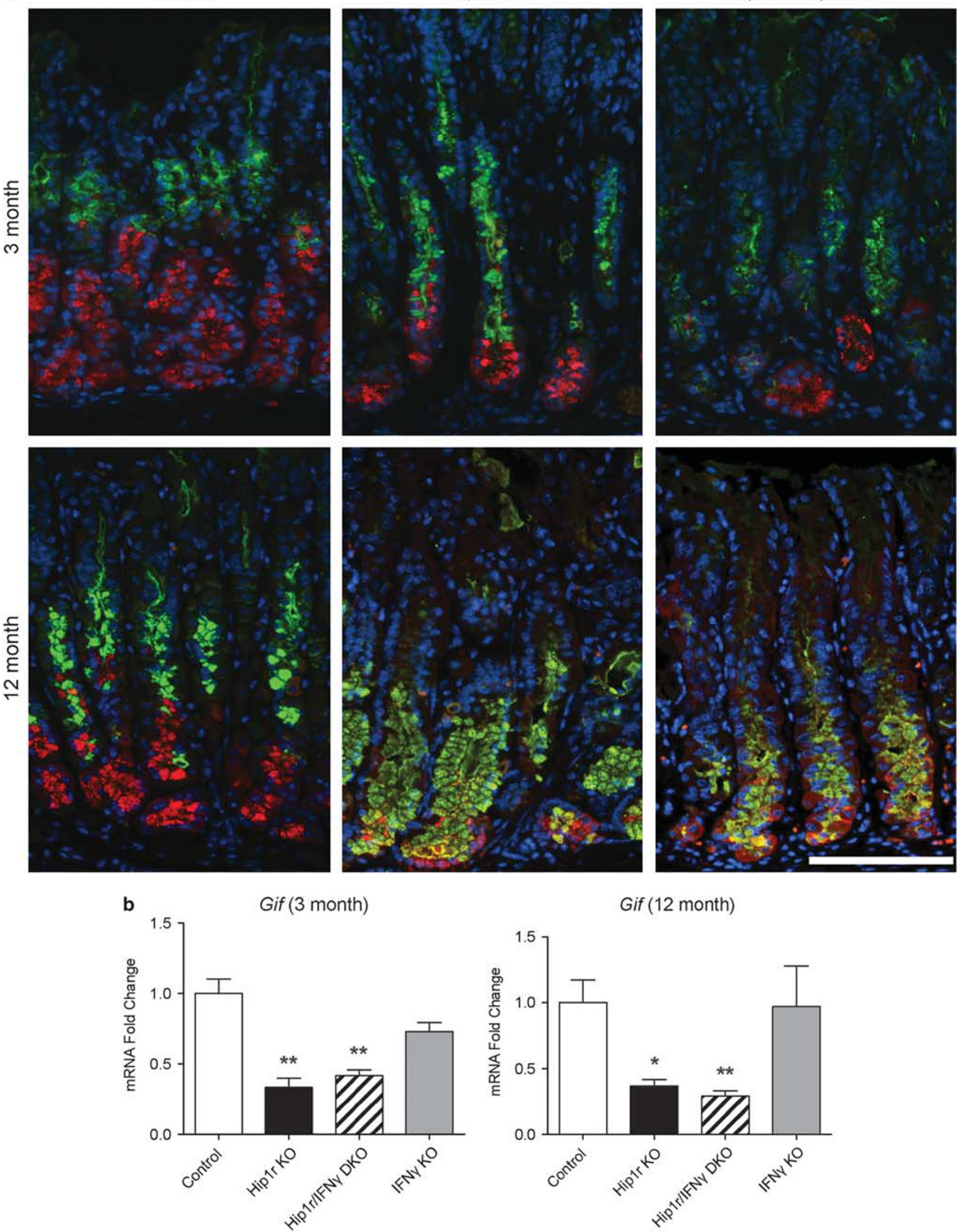
(Figure 4a). Expression of this parietal cell marker was quantified by qRT-PCR measurement of mRNA abundance, confirming a similar reduction in expression in Hip1r-deficient and Hip1r/IFN $\gamma$ double-mutant mice (Figure 4b). These results suggest that the intrinsic defect in Hiplr-deficient parietal cells that results in apoptotic cell death ${ }^{8}$ was not affected by the absence of the pro-inflammatory cytokine IFN $\gamma$.

Our previously published studies had shown significant mucous cell alterations in the Hip1r mutant stomach, including increased numbers of surface mucous cells as well as the development of an aberrant mucous neck/zymogenic cell lineage termed SPEM that occupied the lower half of the affected glands (see Figure 2, arrowheads). ${ }^{8,12}$ This was confirmed by PAS/Alcian blue staining of gastric sections from 12-month-old Hip1r-deficient mice, which showed both increased surface staining and extensive staining in the lower portion of the gastric glands in comparison with controls (Figure 5a). The expanded surface mucous cells were examined further by immunostaining for the surface mucous cell marker Muc5AC (Figure 5b). This staining demonstrated that the Hip1r/IFN $\gamma$ double mutants exhibited a marked expansion of surface mucous cells similar to the Hip1r mutants, suggesting that IFN $\gamma$ is not critical for the surface cell expansion.

Further examination of the PAS/Alcian blue-stained gastric sections in the different groups showed that the stomach of Hip1r/IFN $\gamma$ double mutants differed markedly from the Hip1r mutants. In contrast to Hip1r-deficient mice, the double mutants did not exhibit the extensive neutral (red) and acidic (blue) mucin accumulation in the lower half of the glands (Figure 5a). This result suggested that IFN $\gamma$ contributes to the development of mucous cell metaplasia. Specific staining for mucous cells with GSII showed that Hip1r/ IFN $\gamma$ double-mutant mice had a reduction in mucous cells in comparison with Hip1r-deficient mice at both 3 and 12 months of age, suggesting that IFN $\gamma$ is required to develop the histopathological condition termed SPEM (Figures 2 (arrowheads) and 6a).

SPEM development normally includes loss of differentiated zymogenic cells, ${ }^{5}$ and thus we examined this cell type by immunostaining for the specific marker gastric intrinsic factor. Both Hip1r-deficient mice and Hip1r/IFN $\gamma$ doublemutant mice exhibited similar levels of zymogenic cell loss, shown by reduced immunostaining (Figure 6a, red), as well as reduced levels of gastric intrinsic factor mRNA (Gif) (Figure 6b). Furthermore, both Hip1r-deficient mice and Hip1r/IFN $\gamma$ double mutant mice contained cells at the base of the glands that co-stained for zymogenic and mucous neck cell markers, which is a common feature of SPEM (Figure 6a). These data suggest that IFN $\gamma$ is not responsible for the extensive zymogenic cell changes in Hip1r-deficient mice. Importantly, this analysis suggested that the metaplastic mucous cell expansion, observed by PAS/Alcian blue and GSII staining, is not always reflected by the extent of zymogenic cell changes as the double mutants had an apparent tempering of mucous cell metaplasia in spite of marked zymogenic cell loss and expansion of co-stained cells. This finding suggested that IFN $\gamma$ might directly target the zymogenic lineage to affect the emergence of metaplastic mucous cells.

\section{IFN $\gamma$ Receptor Expression in Mucous Neck Cells}

To study whether IFN $\gamma$ might directly target the zymogenic lineage, the gastric expression of IFN $\gamma$ receptor was studied. Immunostaining for the non-ligand-binding $\beta$ chain, IFNGR2, showed expression in the mid and base regions of the gastric glands, consistent with localization in both mucous neck and zymogenic chief cells (Figure 7). Co-staining for mucous neck cells with GSII demonstrated that expression in the mid region of the gland corresponded to mucous neck cells (Figure 7a). In contrast, co-staining with antibodies to IFNGR2 and $\mathrm{H}^{+}, \mathrm{K}^{+}$ATPase demonstrated no colocalization in parietal cells (Figure $7 \mathrm{~b}$ ). These results suggest that IFN $\gamma$ may directly target the zymogenic lineage to contribute to the development of mucous cell metaplasia in Hip1rdeficient mice.

\section{Cell Proliferation and Glandular Hypertrophy}

The gastric mucosal hypertrophy in Hip1r-deficient mice had been previously demonstrated to result from increased levels of the hormone gastrin in the blood. ${ }^{8}$ As the Hip1r/IFN $\gamma$ double-mutant mice did not show this glandular hypertrophy (Figures 2 and 3), we examined the cellular basis for this effect by measuring cellular proliferation and circulating gastrin levels. Immunostaining for the cell proliferation marker Ki67 and quantification by morphometric analysis confirmed increased numbers of proliferating cells in Hip1rdeficient mice compared with control mice (Figure 8). Proliferating cells were observed to extend to the bottom of the gland in the region occupied by metaplastic mucous cells in the Hiplr-deficient mice. Co-staining for GSII and Ki67 confirmed proliferating mucous cells in this mutant (Figure 8c). In light of the differences in gland height, it was surprising to find that the Hiplr/IFN $\gamma$ double-mutant mice showed similarly increased proliferation as did the Hiplrdeficient mice. However, proliferating mucous cells were rarely observed in the double mutants (Figure 8c). In contrast, proliferating GSII-positive mucous cells were not observed in control mice (not shown).

To test whether IFN $\gamma$ affected circulating levels of gastrin, serum gastrin was quantified by RIA. This analysis showed that both the Hip1r mutant and the Hip1r/IFN $\gamma$ doublemutant mice were hypergastrinemic (Figure 9), which is the likely explanation for the increased proliferation observed in both groups. Together, these results showed that IFN $\gamma$ did not contribute to the hypergastrinemia and increased proliferation in Hip1r-deficient mice. Furthermore, the data showed that increased gastrin levels are associated with increased proliferation.

As loss of IFN $\gamma$ affected GSII-positive mucous cell proliferation, we further examined this cell lineage to determine 
a

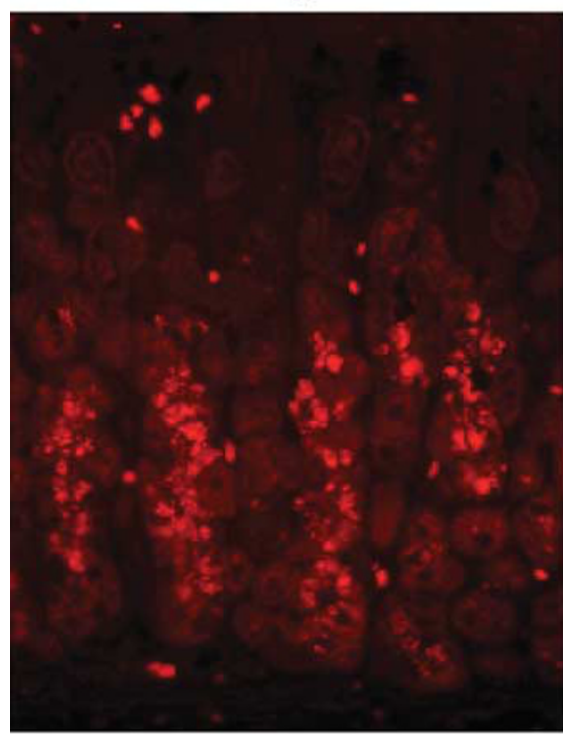

b

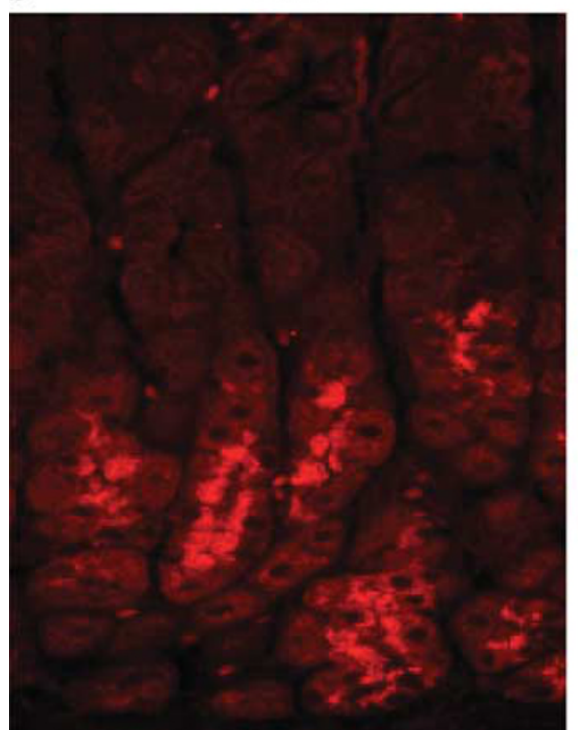

GSII

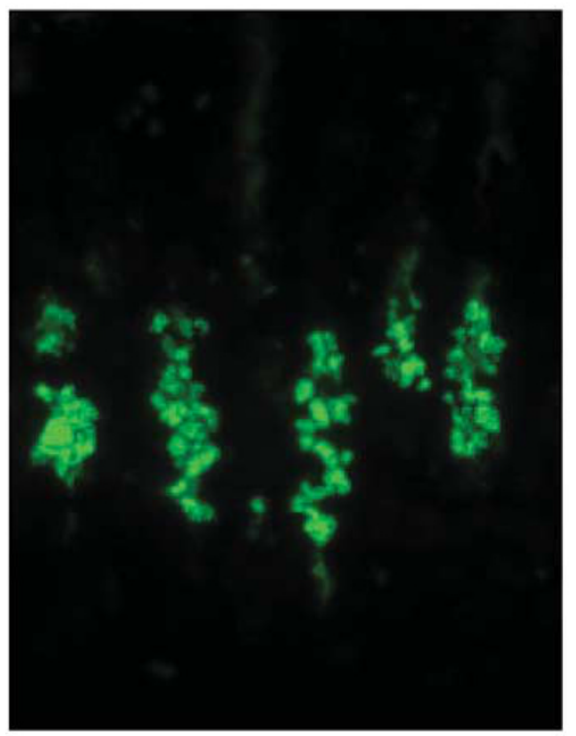

H/K ATPase

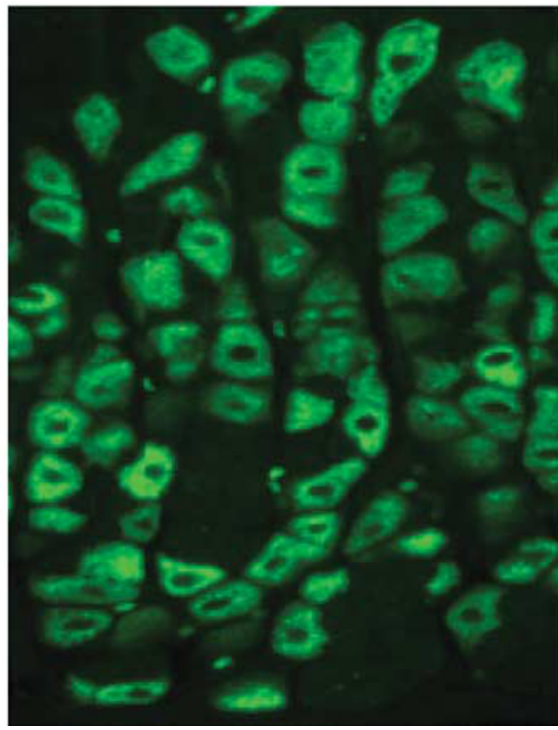

Merged

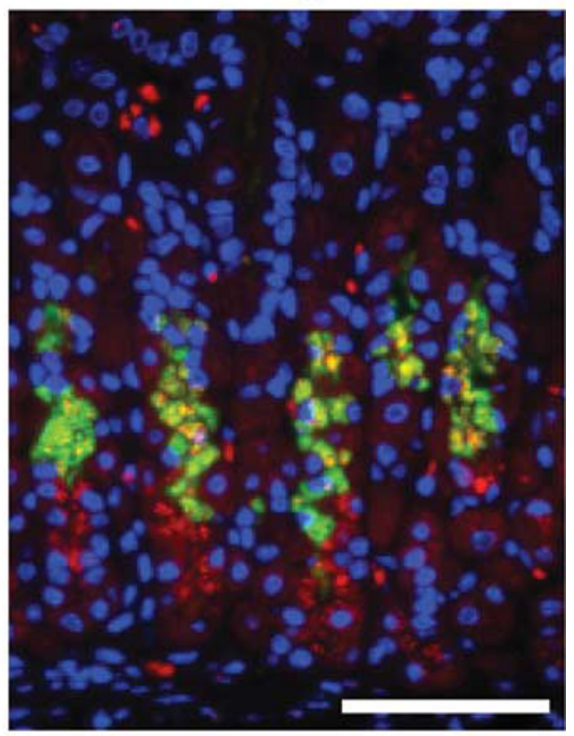

Merged

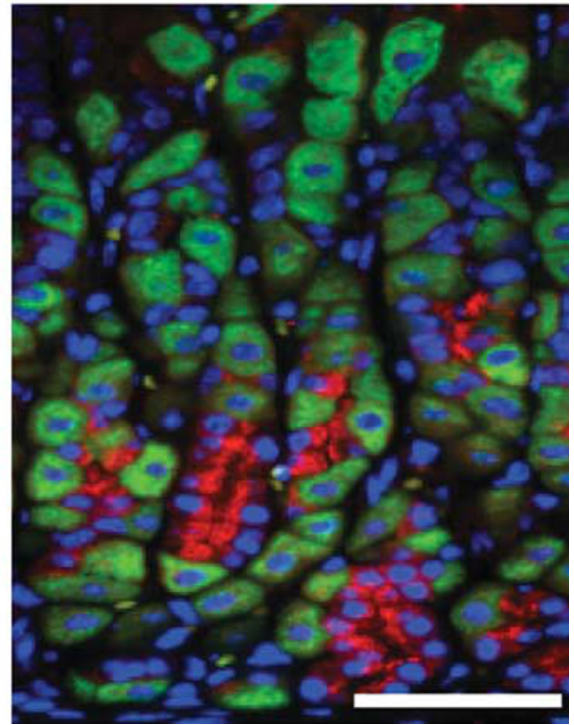

Figure 7 IFN $\gamma$ receptor 2 (Ifngr2) is abundantly expressed in mucous neck cells. Paraffin sections from the corpus of control mice were co-stained with: (a) an antibody directed against Ifngr2 (red) and GSII (green) to examine mucous neck cells, or (b) antibodies to Ifngr2 (red) and $\mathrm{H}^{+}, \mathrm{K}^{+}-\mathrm{ATPase}$ (green) to examine parietal cells. Mucous neck/zymogenic lineage cells stained strongly for Ifngr2 with no obvious staining in parietal cells. DAPI (blue) nuclear stain. Scale bars: $100 \mu \mathrm{m}$.

if alterations in these cells might contribute to the glandular hypertrophy. We hypothesized that expansion of metaplastic mucous cells in Hip1r-deficient mice led to increased gland height. We measured cell size and number after co-immunostaining for the cell membrane marker E-cadherin and GSII. Analysis of confocal images from each group of animals revealed that mucous cells from Hip1r-deficient mice were significantly larger than control mice, and that the loss of IFN $\gamma$ in the double-mutant mice abrogated this phenotype (Figure 10). Mucous cell sizes in IFN $\gamma$-deficient mice were similar to control mice. Furthermore, Hiplr-deficient mice had significantly more mucous cells compared with control mice, and loss of IFN $\gamma$ in the double-mutant normalized mucous cell number. These results allude to the possibility that the elevation in IFN $\gamma$, acting through its receptor on zymogenic lineage cells, can induce gastric gland hypertrophy via increasing mucous cell size and number.

\section{DISCUSSION}

Chronic inflammation has long been considered a critical factor that disrupts gastric epithelial cell homeostasis and contributes to the development of gastric cancer. How 
a

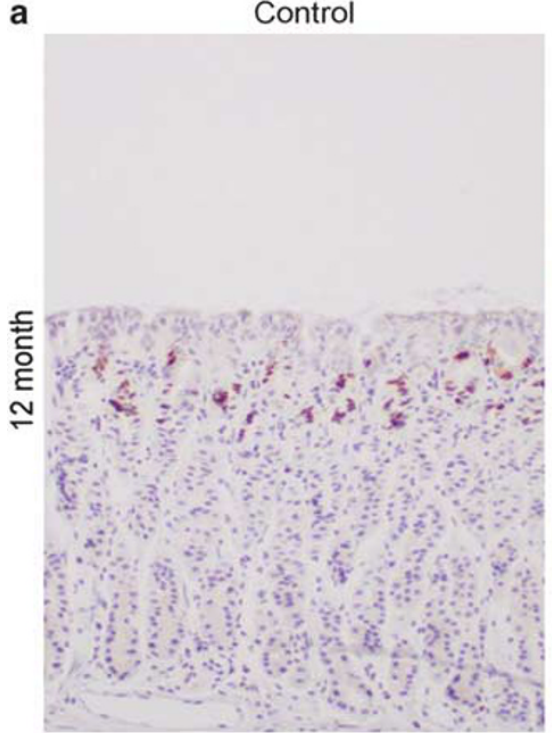

Hip1r KO

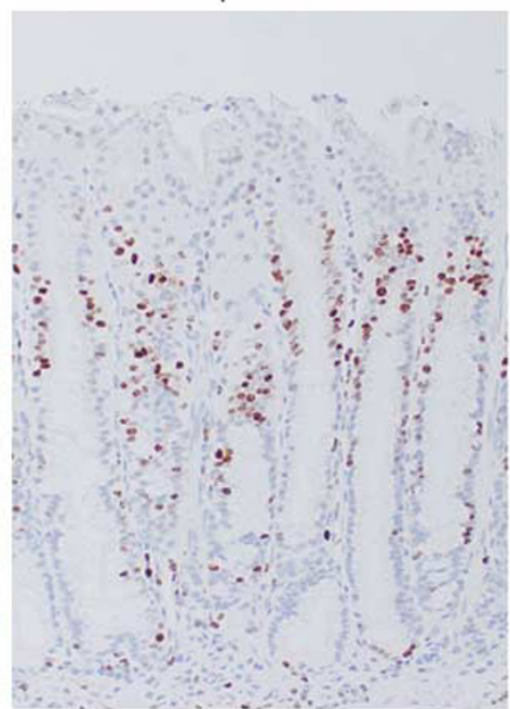

Hip1r/IFNy DKO

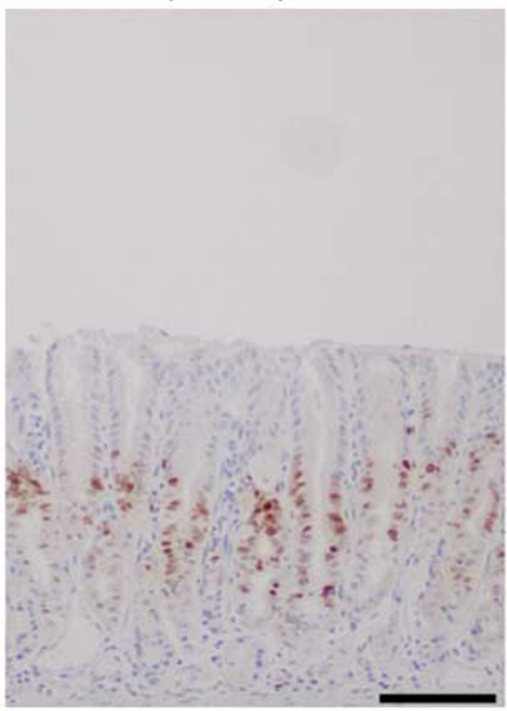

b $\quad \mathrm{Ki67}(3 \mathrm{month})$

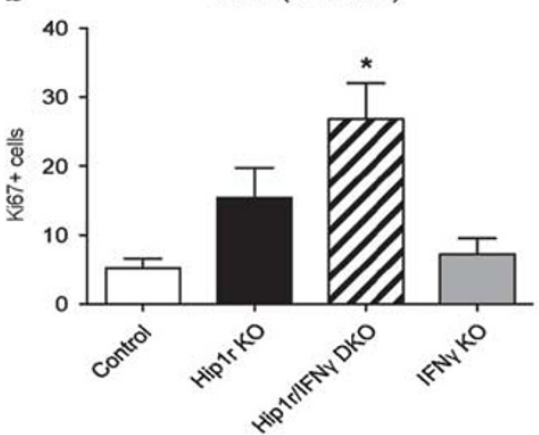

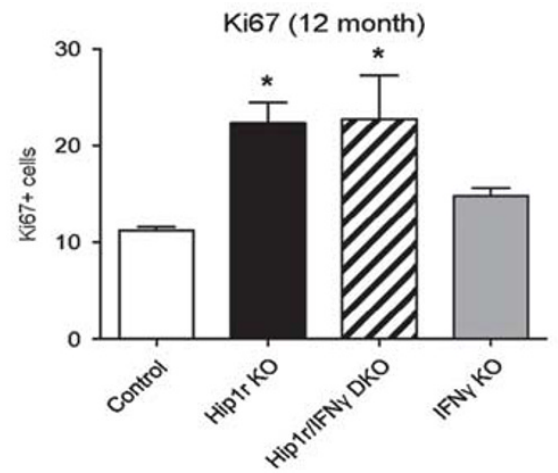

c

Hip1r KO

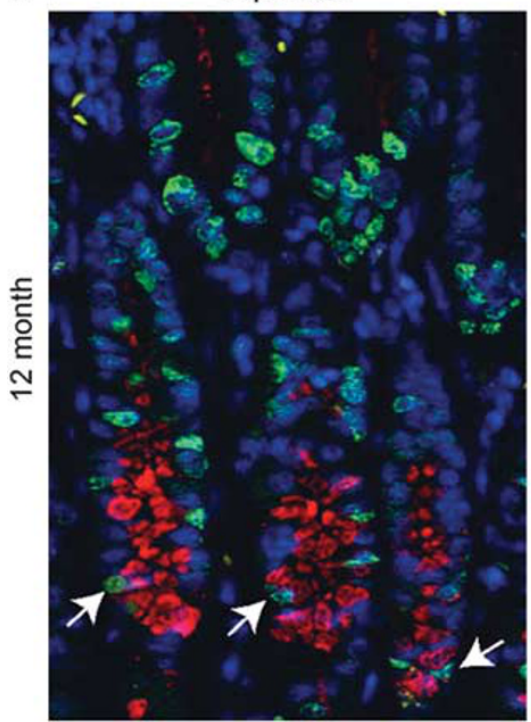

Hip1r/IFNy DKO

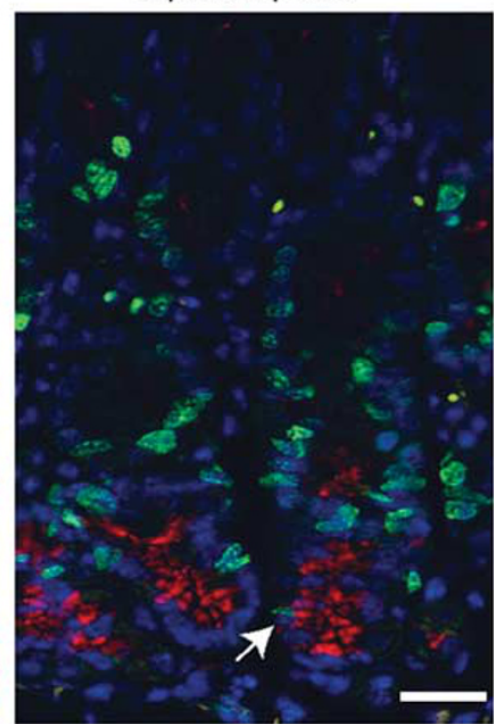

Figure 8 Increased epithelial cell proliferation in Hip1r-deficient mice is not IFN $\gamma$ dependent. (a) Paraffin sections from the corpus of control, Hip1r-KO, Hip1r/IFN $\gamma$-DKO and IFN $\gamma$-KO mice at 12 months of age were stained for the cell proliferation marker Ki67 with hematoxylin counterstain. Scale bar: $100 \mu \mathrm{m}$. (b) Proliferation was quantified by morphometric counting of Ki67-positive cells per gastric gland in 3-month-old $(n=3-5)$ and 12 -month-old $(n=3-5)$ mice. Data are shown as mean \pm s.e.m., with statistical analysis by one-way ANOVA with Bonferroni's post-hoc test ( ${ }^{*} P<0.05$ vs control). (c) Proliferating mucous cells in Hip1r-KO and Hip1r/IFN $\gamma$-DKO mice were assessed by co-immunostaining for Ki67 (green) and GSII (red), and confocal microscopy was used to examine Ki67/GSII double-positive cells (arrows). Scale bar: $20 \mu \mathrm{m}$. 

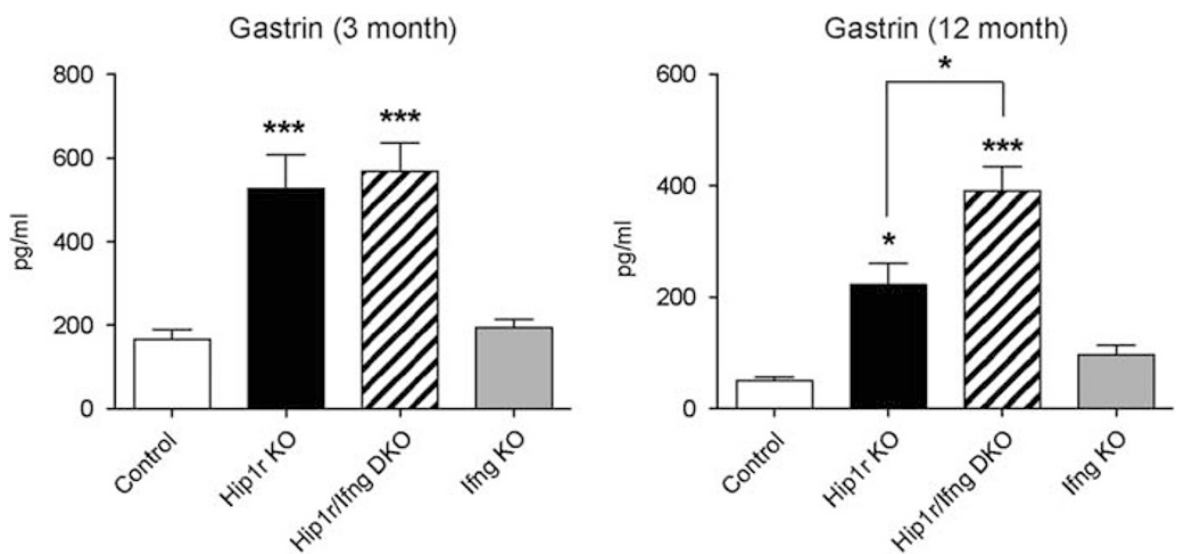

Figure 9 Increased serum gastrin in Hip1r-deficient mice is not IFN $\gamma$ dependent. Serum gastrin levels were measured by radioimmunoassay in 3-month-old $(n=6-9)$ and 12-month-old $(n=3-5)$ mice. Data are shown as mean \pm s.e.m., with statistical analysis by one-way ANOVA with Bonferroni's post-hoc test $\left({ }^{\star} P<0.05\right.$ and ${ }^{\star * *} P<0.001$ vs control or as shown).

immune cells and pro-inflammatory cytokines interact with the complicated gastric epithelial cell architecture and signaling network is an intriguing yet undefined question. In this study, we utilized a unique animal model, Hip1r-deficient mice, which develop progressive gastric epithelial cell lineage alterations because of intrinsic parietal cell loss, to understand the complex events associated with the multifaceted and progressive epithelial cell metaplasia termed SPEM. ${ }^{8,12}$ In this study we focused on the contribution of the cytokine IFN $\gamma$ by intercrossing Hiplr-deficient mice with IFN $\gamma$-deficient mice. The loss of IFN $\gamma$ abrogated specific aspects of the zymogenic lineage metaplasia, but not the parietal cell or surface mucous cell changes (Table 1). Similar to the Hip1r-deficient mice, the double mutants had decreased numbers of zymogenic chief cells and increased numbers of cells expressing both chief and mucous neck cell markers. However, in contrast to the Hip1r-deficient mice, the double mutants did not develop metaplastic mucous cells. Thus, IFN $\gamma$ was necessary for the development of some but not all aspects of SPEM. We also observed that IFN $\gamma$ was not important for increased epithelial cell proliferation or elevated serum gastrin levels in Hip1r-deficient mice. Thus, IFN $\gamma$ appears to play a specific role in the complex cellular changes initiated by parietal cell loss.

Our studies suggest that IFN $\gamma$ targets the zymogenic lineage through a mechanism that affects mucous cell number and size. This finding agrees with the results of a previously published study that showed mucous cell expansion after in vivo administration of IFN $\gamma$ to $\mathrm{C} 57 \mathrm{BL} / 6$ mice. ${ }^{21}$ Further in vitro analysis showed that IFN $\gamma$ stimulation of NCI-N87 gastric cancer cells induced increased expression of the mucous neck cell markers Muc6 and TFF2, and, importantly, induced a significant increase in cell size similar to what we observed in the Hip1r-deficient mice. ${ }^{21}$ These studies, together with our observation of abundant IFNGR2 expression in the zymogenic lineage, are consistent with the notion that IFN $\gamma$ can directly and preferentially target these gastric epithelial cells. Whether IFN $\gamma$ is sufficient to trigger gastric metaplasia has been recently addressed by specific transgenic expression of this cytokine in the mouse stomach. ${ }^{23,24}$ Although a low level of expression of this cytokine was not observed to induce gastric epithelial cell changes, ${ }^{23}$ higher levels triggered a profound and rapid mucous cell metaplasia. ${ }^{24}$

The expansion of a metaplastic mucous cell population is a common characteristic of the pre-neoplastic metaplasia known as SPEM. Hip1r-deficient mice develop SPEM as a likely consequence of spontaneous apoptotic parietal cell death that occurs in this mutant. ${ }^{8,12}$ Acute administration of the drug DMP-777, which rapidly induces parietal cell loss, has been shown to cause SPEM development without obvious inflammation in both rats $^{25}$ and mice. ${ }^{6}$ This finding indicates that parietal cell loss itself is sufficient to induce SPEM. However, use of the drug L-635, which induces rapid parietal cell loss accompanied by the induction of a prominent inflammatory cell infiltrate, resulted in a more aggressive development of mucous cell metaplasia, supporting the conclusion that inflammatory mediators play a critical role in SPEM development. ${ }^{6}$

In our study, parietal cell loss in the absence of IFN $\gamma$ does not appear to induce the complete SPEM phenotype, even when Hip1r/IFN $\gamma$ double-mutant mice were aged to 12 months. Aspects of the SPEM phenotype that were preserved in the absence of IFN $\gamma$ include the loss of zymogenic cells and the expansion of cells at the base of the gland that coexpresses mucous neck cell (GSII) and zymogenic chief cell (intrinsic factor) markers. Parietal cells are critically important for zymogenic chief cell differentiation, and loss of parietal cells is associated with the rapid loss of zymogenic cells, reportedly by both apoptotic cell death ${ }^{12}$ and transdifferentiation into the SPEM lineage. ${ }^{6}$ How parietal cells mediate this effect is unknown, although it has been suggested that parietal cells might secrete an essential growth factor required for zymogenic cell differentiation. ${ }^{26,27}$ 
a

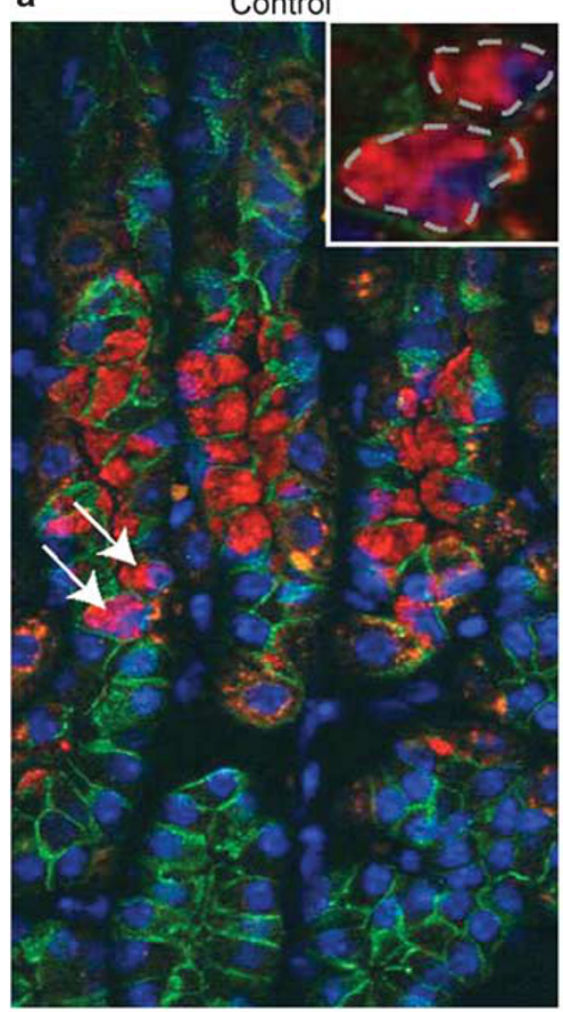

b

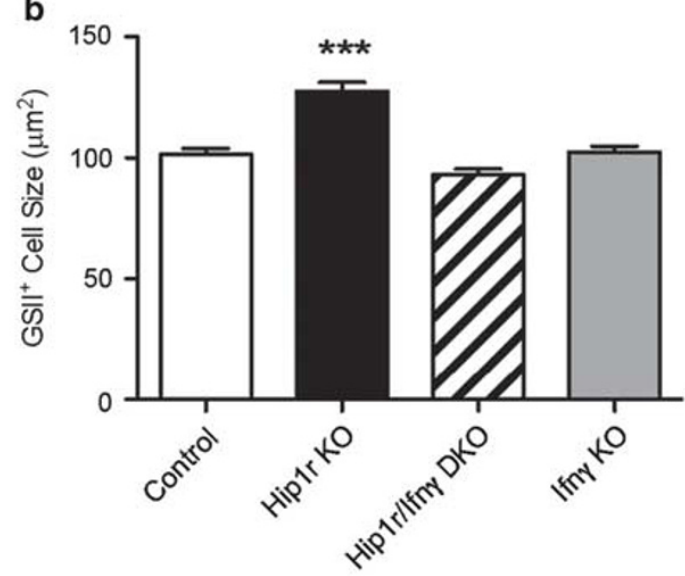

Hip1r KO
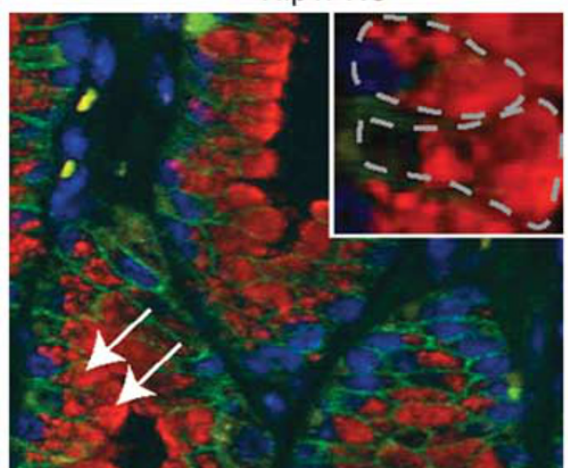
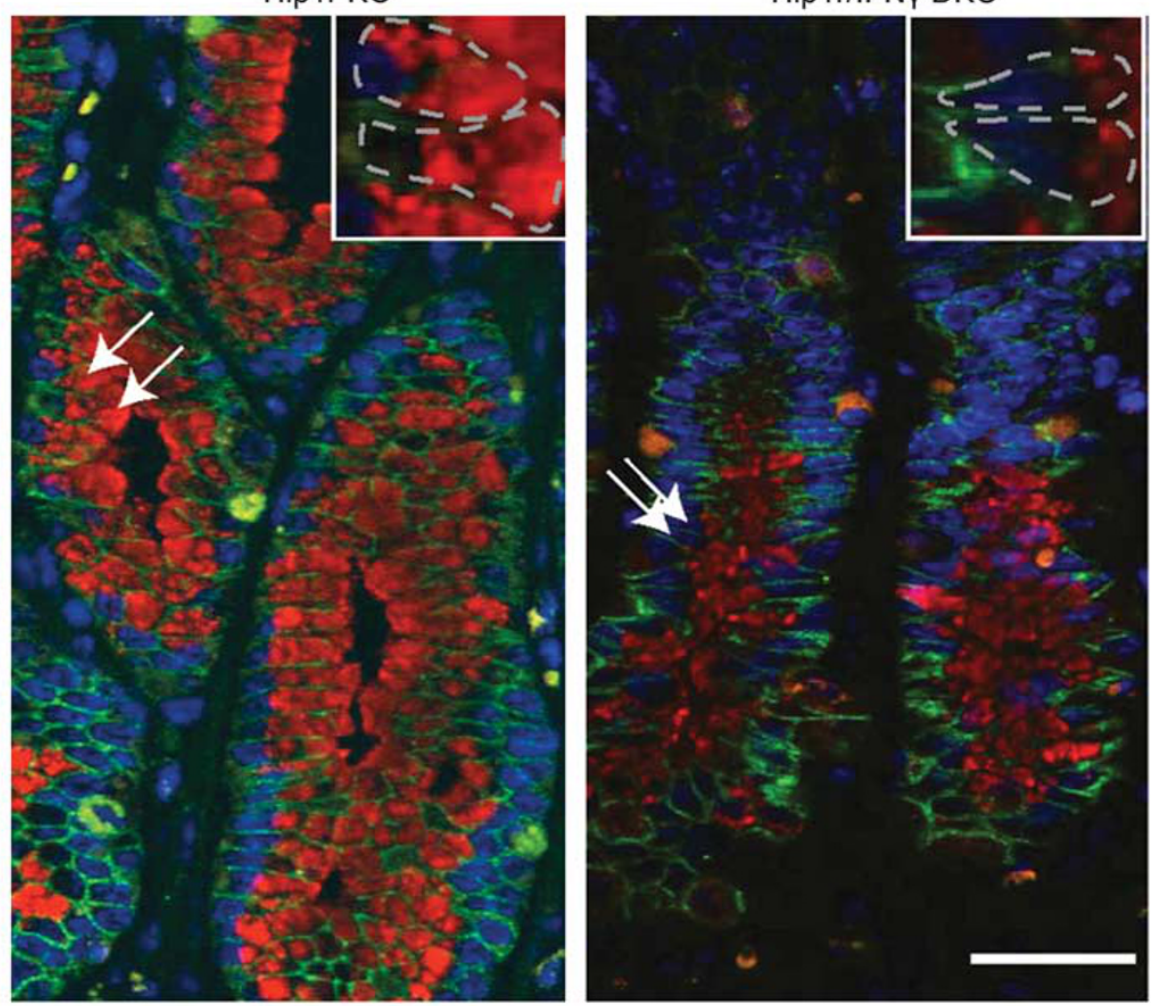

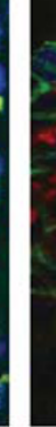

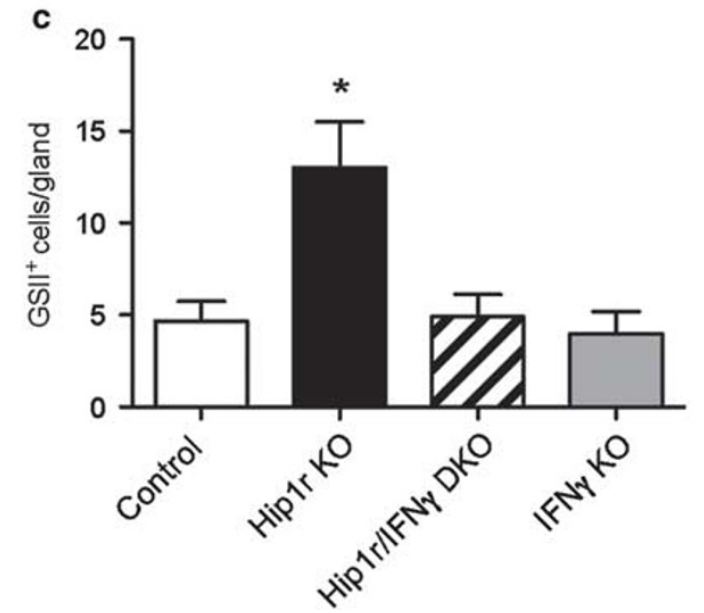

Figure 10 Increased mucous cell number and size in Hip1r-deficient mice. (a) Paraffin sections from the corpus of control, Hip1r-KO, Hip1r/IFN $\gamma$-DKO and IFN $\gamma$-KO mice at 12 months of age were co-stained with an antibody to E-cadherin (green) and GSII (red) and images collected by confocal microscopy. Arrows point to some mucous cells with insets showing higher powered views. Scale bar: $20 \mu \mathrm{m}$. (b) Quantification of cell size in control ( $n=101)$, Hip1r-KO $(n=81), \mathrm{Hip} 1 \mathrm{r} / \mathrm{IFN} \gamma$-DKO $(n=63)$ and IFN $\gamma$-KO $(n=70)$ mucous cells. Data are shown as mean \pm s.e.m., with statistical analysis by one-way ANOVA with Bonferroni's post-hoc test (***P<0.001 vs all groups). (c) Quantification of mucous cell number in control $(n=6), \mathrm{Hip} 1 \mathrm{r}-\mathrm{KO}(n=10), \mathrm{Hip} 1 \mathrm{r} / \mathrm{IFN} \gamma$-DKO $(n=4)$ and IFN $\gamma$-KO $(n=3)$ mice. Data are shown as mean \pm s.e.m., with statistical analysis by one-way ANOVA with Bonferroni's post-hoc test $\left({ }^{*} P<0.05\right.$ vs control).

In summary, our studies show that the gastritis that develops upon apoptotic loss of parietal cells in the Hip1rdeficient mouse includes increased expression of the proinflammatory cytokine IFN $\gamma$. IFN $\gamma$ plays a unique role in the metaplastic lineage changes that occur in the gastric mucosa, specifically targeting hypertrophy and hyperplasia of mucous cells in the zymogenic lineage. Although our studies support a possible direct effect of IFN $\gamma$ to contribute to the preneoplastic SPEM phenotype, it is likely that these cells might be sensitive to a number of inflammatory mediators and thus the effects of IFN $\gamma$ could also be indirect. Furthermore, our study demonstrates that different aspects of the SPEM phenotype are mediated by distinct mechanisms, with loss of zymogenic cells likely due to the loss of an essential, and as 
Table 1 Summary of gastric epithelial cell features in Hip1r-deficient mice and Hip1r/IFN $\gamma$ double-mutant mice

\begin{tabular}{|c|c|c|c|}
\hline Cell type & Marker & Hip1r-KO & $\begin{array}{l}\text { Hip1r/IFN } \gamma \\
\text { DKO }\end{array}$ \\
\hline Surface mucous & Muc5AC & Hyperplastic & Hyperplastic \\
\hline Proliferative progenitor & Ki67 & Increased & Increased \\
\hline Parietal & $\mathrm{H}^{+}, \mathrm{K}^{+}$-ATPase & Decreased & Decreased \\
\hline \multicolumn{4}{|l|}{ Zymogenic lineage } \\
\hline Mucous neck & GSII lectin & $\begin{array}{l}\text { Hyperplastic/ } \\
\text { hypertrophied }\end{array}$ & Normal $^{a}$ \\
\hline Transition & GSII and GIF & Increased & Increased \\
\hline Zymogenic chief & GIF & Decreased & Decreased \\
\hline
\end{tabular}

Abbreviations: DKO, double knockout; GIF, gastric intrinsic factor; GSII, Griffonia simplicifolia lectin II; KO, knockout; Muc5AC, mucin 5 AC.

a Loss of IFN $\gamma$ protects against the spontaneous development of the mucous cell changes observed in the neck region of Hip1r-deficient glands.

Cellular features, described in comparison with wild type, were determined by mRNA abundance and immunohistochemical analysis of cell-specific markers in 12-month-old Huntingtin interacting protein 1-related (Hip 1r)-deficient mice and Hip1r/IFN $\gamma$ double-mutant mice.

yet undefined, parietal cell factor, whereas pro-inflammatory cytokines, including IFN $\gamma$, contribute to the development of mucous cell metaplasia. Future studies should be directed toward understanding how inflammatory mediators might directly regulate the zymogenic lineage during metaplastic transformation.

\section{ACKNOWLEDGEMENTS}

We acknowledge Jianhua Ren for initiating this analysis, Allison Hoch for maintenance of the mouse colonies and the morphology core of the University of Michigan Gastrointestinal Peptide Center for assistance with confocal microscopy. This study was supported by National Institute of Diabetes and Digestive and Kidney Diseases (NIDDK) Grant RO1-DK-078926 (to LC Samuelson) and PO1-DK-062041 (to JL Merchant). Core support was provided by NIDDK Gastrointestinal Hormone Research Center Grant P30DK-34933.

\section{DISCLOSURE/CONFLICT OF INTEREST}

The authors declare no conflict of interest.

1. Ferlay J, Shin HR, Bray F, et al. Estimates of worldwide burden of cancer in 2008: GLOBOCAN 2008. Int J Cancer 2010;127:2893-2917.

2. Polk DB, Peek Jr RM. Helicobacter pylori: gastric cancer and beyond. Nat Rev Cancer 2010;10:403-414.

3. Correa P. A human model of gastric carcinogenesis. Cancer Res 1988:48:3554-3560.

4. Fox JG, Wang TC. Inflammation, atrophy, and gastric cancer. J Clin Invest 2007;117:60-69.

5. Goldenring JR, Nam KT, Mills JC. The origin of pre-neoplastic metaplasia in the stomach: chief cells emerge from the Mist. Exp Cell Res 2011;317:2759-2764.
6. Nam KT, Lee HJ, Sousa JF, et al. Mature chief cells are cryptic progenitors for metaplasia in the stomach. Gastroenterology 2010; 139:2028-U2324.

7. Nomura $\mathrm{S}$, Yamaguchi $\mathrm{H}$, Ogawa $\mathrm{M}$, et al. Alterations in gastric mucosal lineages induced by acute oxyntic atrophy in wild-type and gastrindeficient mice. Am J Physiol Gastrointest Liver Physiol 2005;288: G362-G375.

8. Jain RN, Al-Menhali AA, Keeley TM, et al. Hip1r is expressed in gastric parietal cells and is required for tubulovesicle formation and cell survival in mice. J Clin Invest 2008;118:2459-2470.

9. Judd LM, Gleeson PA, Toh BH, et al. Autoimmune gastritis results in disruption of gastric epithelial cell development. Am J Physiol 1999;277(1 Pt 1):G209-G218.

10. Lopez-Diaz L, Hinkle $\mathrm{KL}$, Jain $\mathrm{RN}$, et al. Parietal cell hyperstimulation and autoimmune gastritis in cholera toxin transgenic mice. Am J Physiol Gastrointest Liver Physiol 2006;290:G970-G979.

11. Wang TC, Goldenring JR, Dangler C, et al. Mice lacking secretory phospholipase A2 show altered apoptosis and differentiation with Helicobacter felis infection. Gastroenterology 1998;114:675-689.

12. Keeley TM, Samuelson LC. Cytodifferentiation of the postnatal mouse stomach in normal and Huntingtin-interacting protein 1-relateddeficient mice. Am J Physiol Gastrointest Liver Physiol 2010;299: G1241-G1251.

13. El-Omar EM, Carrington $\mathrm{M}, \mathrm{Chow} \mathrm{WH}$, et al. The role of interleukin-1 polymorphisms in the pathogenesis of gastric cancer. Nature 2001; 412:99.

14. Figueiredo $\mathrm{C}$, Machado JC, Pharoah $\mathrm{P}$, et al. Helicobacter pylori and interleukin 1 genotyping: an opportunity to identify high-risk individuals for gastric carcinoma. J Natl Cancer Inst 2002;94:1680-1687.

15. Tu S, Bhagat G, Cui G, et al. Overexpression of interleukin-1beta induces gastric inflammation and cancer and mobilizes myeloidderived suppressor cells in mice. Cancer Cell 2008;14:408-419.

16. Sawai $N$, Kita $M$, Kodama $T$, et al. Role of gamma interferon in Helicobacter pylori-induced gastric inflammatory responses in a mouse model. Infect Immun 1999;67:279-285.

17. Smythies LE, Waites KB, Lindsey JR, et al. Helicobacter pylori-induced mucosal inflammation is Th1 mediated and exacerbated in IL-4, but not IFN-gamma, gene-deficient mice. J Immunol 2000;165:1022-1029.

18. Mueller A, Merrell DS, Grimm J, et al. Profiling of microdissected gastric epithelial cells reveals a cell type-specific response to Helicobacter pylori infection. Gastroenterology 2004;127:1446-1462.

19. Eaton KA, Mefford $M$, Thevenot $T$. The role of $T$ cell subsets and cytokines in the pathogenesis of Helicobacter pylori gastritis in mice. $\mathrm{J}$ Immunol 2001;166:7456-7461.

20. Sayi A, Kohler E, Hitzler I, et al. The CD4+ T cell-mediated IFN-gamma response to Helicobacter infection is essential for clearance and determines gastric cancer risk. J Immunol 2009;182:7085-7101.

21. Kang W, Rathinavelu S, Samuelson LC, et al. Interferon gamma induction of gastric mucous neck cell hypertrophy. Lab Invest 2005;85:702-715.

22. Hyun TS, Li L, Oravecz-Wilson Kl, et al. Hip1-related mutant mice grow and develop normally but have accelerated spinal abnormalities and dwarfism in the absence of HIP1. Mol Cell Biol 2004;24:4329-4340.

23. Tu SP, Quante $M$, Bhagat $G$, et al. IFN-gamma inhibits gastric carcinogenesis by inducing epithelial cell autophagy and T-cell apoptosis. Cancer Res 2011;71:4247-4259.

24. Syu L-J, Ferris J, Qiao X, et al. Transgenic expression of interferon gamma in the gastric corpus leads to inflammation, progenitor cells expansion and mucous metaplasia. Gastroenterology 2010;138 (Suppl 1):S83.

25. Goldenring JR, Ray GS, Coffey RJ, et al. Reversible drug-induced oxyntic atrophy in rats. Gastroenterology 2000;118:1080-1093.

26. Capoccia BJ, Huh WJ, Mills JC. How form follows functional genomics: gene expression profiling gastric epithelial cells with a particular discourse on the parietal cell. Physiol Genomics 2009;37:67-78.

27. Jain RN, Brunkan CS, Chew CS, et al. Gene expression profiling of gastrin target genes in parietal cells. Physiol Genomics 2006;24:124-132. 